REVISTA X, Curitiba, volume 12, n.3, p.01-17, 2017.

\title{
UM ESTUDO SOBRE OS NOVOS LETRAMENTOS NA FORMAÇÃO DE PROFESSORES DE INGLÊS ${ }^{1}$
}

\author{
A Study on New Literacies in English Teacher Education
}

\author{
Walter Vieira BARROS ${ }^{2}$ - UFCG \\ Marco Antônio Margarido COSTA ${ }^{3}$ - UFCG
}

RESUMO: Este artigo apresenta parte dos resultados de uma pesquisa (PIBIC/CNPq 2015-2016) que investigou práticas pedagógicas orientadas pela perspectiva dos novos letramentos em cursos de formação de professores de língua inglesa. Tal perspectiva teórica busca capacitar o professor para atender às novas formas de comunicação e construção de conhecimento da sociedade atual - globalizada, tecnologizada, heterogênea e complexa (COPE; KALANTZIS, 2000; MATTOS, 2015; MENEZES DE SOUZA, 2011a). Para essa investigação, adotamos como objeto de análise a obra Novos letramentos, formação de professores e ensino de língua inglesa (ZACCHI; STELLA, 2014) por apresentar práticas pedagógicas realizadas por professores envolvidos em cursos de formação em diferentes estados do Brasil. Foi realizado o estudo dos dez capítulos que compõem a obra, visando identificar quais práticas apresentavam de forma mais evidente os fundamentos dos novos letramentos. A análise dessas práticas teve como base a atualização dos estudos de Kalantzis e Cope (2005) acerca dos movimentos pelos quais o conhecimento se constitui: 'experienciar', 'conceituar', 'analisar' e 'aplicar'. Com nossa análise, percebemos, por exemplo, que as práticas que apresentaram os fundamentos dessas teorias foram as que utilizaram a disciplina de língua inglesa como meio (ARAÚJO, 2000, p. 98) para se alcançar objetivos mais educacionais e formativos do aluno/cidadão.

PALAVRAS-CHAVE: Formação de Professores de Inglês; Sociedade Contemporânea; Novos Letramentos.

ABSTRACT: This paper presents part of the results from a research (PIBIC/CNPq 2015-2016) which investigated pedagogical practices guided by the new literacies perspective in English teacher education courses. This theoretical perspective seems to better prepare teachers to deal with new forms of communication and meaning making

\footnotetext{
${ }^{1}$ Este artigo tem como base a pesquisa intitulada: "Práticas orientadas pelos novos letramentos na formação de professores de inglês", desenvolvida pelo Programa Institucional de Bolsas de Iniciação Científica (PIBIC), com o apoio do Conselho Nacional de Desenvolvimento Científico e Tecnológico Brasil (CNPq), na Universidade Federal de Campina Grande (UFCG) com vigência de agosto de 2015 a julho de 2016.

2 Mestrando e bolsista (CAPES) do Programa de Pós-Graduação em Linguagem e Ensino da Universidade Federal de Campina Grande - UFCG. E-mail: waltervieirabarros@gmail.com

${ }^{3}$ Doutor em Letras pela Faculdade de Filosofia, Letras e Ciências Humanas da Universidade de São Paulo - FFLCH/USP. Professor da Unidade Acadêmica de Letras da Universidade Federal de Campina Grande - UFCG. E-mail: marcoantoniomcosta@gmail.com
} 
in today's society - globalized, technologized, heterogeneous, and complex (COPE; KALANTZIS, 2000; MATTOS, 2015; MENEZES DE SOUZA, 2011a). In order to accomplish such investigation, Novos letramentos, formação de professores e ensino de lingua inglesa (ZACCHI; STELLA, 2014) was used as the analysis object once it presents pedagogical practices from different Brazilian states, employed by teachers involved in teacher education courses. The ten chapters that compose the book were studied in order to identify which practices presented the new literacies bases more evidently. The analysis of such practices was based on Kalantzis and Cope's (2005) studies update of the movements by which knowledge is constructed: 'experiencing', 'conceptualising', 'analysing', and 'applying'. One of the results of the analysis was that the practices which presented the bases of the theoretical perspective adopted here were those ones which used English language discipline as means (ARAÚJO, 2000, p. 98) to achieve educational and formative goals in the learner's/citizen's schooling.

KEYWORDS: English Teacher Education; Contemporary Society; New Literacies.

\section{INTRODUÇÃO}

Neste artigo, apresentamos parte dos resultados de uma pesquisa de iniciação científica (PIBIC/CNPq 2015-2016), que investigou práticas pedagógicas orientadas pela perspectiva dos novos letramentos em cursos de formação de professores de língua inglesa em diferentes contextos educacionais brasileiros.

Essa pesquisa teve como objeto de análise o livro Novos letramentos, formação de professores e ensino de língua inglesa (ZACCHI; STELLA, 2014), uma vez que a obra apresenta estudos que foram empreendidos por pesquisadores brasileiros de diversas IES (UFPR, UFS, UFAL, UFMG, UFRRJ, UFCG e UEMS), de diferentes estados, que estão envolvidos com o Projeto Nacional Novos Letramentos. ${ }^{4}$

Iniciamos a pesquisa com um aprofundamento teórico da literatura sobre os novos letramentos, bem como a leitura do material de análise, a saber: 10 (dez) textos reunidos no livro supramencionado. Em seguida, foi feito o estudo desse material visando à identificação dos tipos de propostas empreendidas em cada texto (objetivo das práticas realizadas), à maneira como cada prática foi realizada (procedimentos metodológicos) e os resultados obtidos com tais práticas, a fim de compreender como os pressupostos dos novos letramentos contribuíram com o ensino da língua inglesa ou

\footnotetext{
${ }^{4}$ O Projeto Nacional Novos Letramentos é coordenado pelos professores Walkyria Monte Mór e Lynn Mario T. Menezes de Souza, ambos da Universidade de São Paulo.
} 
com a formação de professores dessa LE em cada texto apresentado na coletânea referenciada.

$\mathrm{Na}$ análise, buscamos enfatizar em quais aspectos da formação docente (saberes, processos de identificação, metodologias, políticas educacionais etc.) as práticas pedagógicas baseadas nos estudos dos novos letramentos provocaram maiores impactos nos professores e/ou alunos em cursos de Letras (língua inglesa).

Para isso, selecionamos os fragmentos que melhor evidenciam os pressupostos dos novos letramentos. Ademais, também adotamos os estudos de Kalantzis e Cope (2005) sobre os princípios da pedagogia dos multiletramentos com o intuito de identificar e categorizar esses fragmentos selecionados para análise, de acordo com os quatro movimentos (experienciar, conceituar, analisar e aplicar) pelos quais, segundo esses autores, o conhecimento se constitui.

Desse modo, os objetivos gerais da pesquisa foram: 1) contribuir para a reflexão em torno da formação de professores de língua inglesa e do seu ensino; 2) fornecer subsídios de análise acerca da inserção das teorias dos novos letramentos nos cursos de formação de professores de línguas. Como objetivos específicos, elencam-se: a) estudar as práticas pedagógicas orientadas pela perspectiva dos novos letramentos em cursos de formação de professores de inglês a partir da análise de capítulos apresentados no livro "Novos letramentos, formação de professores e ensino de língua inglesa"; b) analisar a natureza das atividades docentes apresentadas e a maneira pela qual são planejadas e executadas nos cursos investigados; e c) avaliar as implicações apontadas nos licenciandos dos cursos investigados que estão vinculados à perspectiva teórica adotada.

Logo, as perguntas norteadoras da pesquisa foram: a) quais práticas pedagógicas mostram, de forma mais evidente, os fundamentos dos novos letramentos?, b) que consequências tais práticas provocaram nos sujeitos envolvidos (professores e/ou alunos) em cada estudo analisado? e c) em que medida essas referidas práticas delineiam o perfil do professor de inglês na contemporaneidade?

\section{O PROFESSOR DE LÍNGUA (INGLESA) NA CONTEMPORANEIDADE}

Não se pode negar que os processos de globalização e o advento das novas tecnologias provocam inúmeras e incessantes transformações em todos os setores (educacional, profissional, pessoal etc.) da sociedade atual. Além de estarmos vivenciando constantes mudanças que vêm ocorrendo em diversos setores da sociedade 
e de estarmos diante de um mundo cada vez mais "tecnologizado" (KNOBEL; LANKSHEAR, 2007, p. 10), os processos de globalização propiciam o contato com diferentes culturas ao redor do mundo. Com isso, evidencia-se que cada contexto possui características próprias, sendo, portanto, a linguagem praticada de modo contextualizado em diferentes sociedades, diferentes comunidades, que usam diferentes formas para se expressarem (KRESS, 2000).

A presença das novas tecnologias na sociedade contemporânea e a compreensão de que falantes de diferentes línguas e culturas ao redor do mundo estão em contato constante nos fazem perceber um emergir crescente de diversidades locais que, embora tenham suas especificidades, estão em conectividade com o global, estabelecendo, assim, uma relação em que o global influencia e é influenciado pelo local (MATTOS, 2015). Essa característica heterogênea e plural da sociedade, devido à constante relação entre o global e o local, também é percebida nas diferentes formas e manifestações de linguagem utilizadas no mundo atual. Assim, pensadores como Knobel e Lankshear (2007) e Cope e Kalantzis (2000) adotaram a expressão 'novos letramentos' para designar as novas habilidades ou as novas maneiras de se pensar e de se aprender que devem ser adquiridas/desenvolvidas em um contexto tecnológico/digital na contemporaneidade.

A educação também tem sido fortemente influenciada pelos avanços do mundo tecnológico e globalizado (COPE; KALANTZIS, 2000). Com isso, entendemos que seria importante que as instituições escolares buscassem acompanhar e se adaptar às exigências dessas novas formas de comunicação na contemporaneidade. Se o aprendizado se dá mediante a exposição ao outro (outra língua, outro contexto, outro indivíduo etc.), os profissionais da área de linguagem poderiam desenvolver nos aprendizes capacidades de negociação nas sociedades que usam diversas formas para se expressarem. Isso porque ao tratarmos do ensino-aprendizagem de línguas em uma sociedade plural e heterogênea, um ensino focado apenas em "padrões" universais não parece condizente com as necessidades de tal contexto, uma vez que os falantes acomodam suas variações locais no uso da língua. Para exemplificar esse processo de acomodação ou reivindicação local, Canagarajah (2006) refere-se à língua inglesa e à forma como esta tem sido usada como língua estrangeira ou segunda língua, em que 
falantes multilíngues resistem ao uso de formas dominantes do inglês e encontram maneiras de acomodar suas variantes locais.

Vale ressaltar que esse processo de resistência, de reivindicação local, acontece em relação a qualquer forma dominante de uso da uma língua que seja imposta como universal/padrão, por haver um apagamento da complexidade inerente às comunidades e aos membros que as constituem e que, portanto, influencia na forma que a linguagem é utilizada (MENEZES DE SOUZA, 2011a).

Portanto, é necessário investir em práticas pedagógicas que considerem as mudanças que vêm ocorrendo na sociedade e os impactos dessas para a educação, valorizando o diferente, o heterogêneo e o complexo no intuito de diminuir o descompasso entre escola e sociedade (MENEZES DE SOUZA, 2011a), além de preparar o aluno para se engajar ativamente nessa sociedade complexa e heterogênea. Por essa razão, acreditamos que, dentre várias possibilidades, valorizar e incorporar os pressupostos dos novos letramentos em cursos de formação de professores seja um dos caminhos possíveis para que esses profissionais consigam atender às novas formas de comunicação e de construção de conhecimento na sociedade atual. Por isso, a importância da pesquisa realizada (PIBIC/CNPq 2015-2016), cuja proposta foi investigar práticas pedagógicas orientadas pela perspectiva dos novos letramentos em cursos de formação de professores de língua inglesa em contextos educacionais diversos em diferentes estados brasileiros.

Acreditamos que a perspectiva teórica e filosófica dos novos letramentos, pelo viés do letramento crítico, nos ajuda a pensar sobre a maneira como a materialidade linguística reflete uma prática social (e, por conseguinte, uma ideologia). Conforme destaca Monte Mór (2013, p. 42), "o letramento crítico [como uma vertente dos novos letramentos] parte da premissa de que linguagem tem natureza política, em função das relações de poder nela presentes". Vem também dessa pesquisadora a noção de “expansão de perspectivas” (cf. MONTE MÓR, 2013), que está relacionada ao desenvolvimento da construção de uma reflexão crítica que visa provocar deslocamentos a respeito de concepções socialmente construídas. Pensar, então, sobre a formação de professores na perspectiva dos novos letramentos implica uma preparação do futuro docente para o reconhecimento e a compreensão de diversas formas de comunicação e construção de conhecimento, formas essas que dialogam e se articulam. 
A construção dessa criticidade na formação de professores deve levar em consideração as diferentes interpretações dos fenômenos linguísticos em um processo denominado de meaning making (construção de sentido) (MENEZES DE SOUZA, 2011b; CERVETTI; PARDALES; DAMICO, 2001). Os professores que consideram tal processo parecem adequar suas práticas às exigências da sociedade contemporânea. Sociedade essa que se torna cada vez mais digital, o que implica, também, a incorporação desse meio virtual às práticas que consideram o processo de meaning making, ao invés, por exemplo, de utilizá-lo apenas como um suporte para práticas tradicionais (KALANTZIS; COPE, 2005).

Assim, requer-se uma ampliação do conceito de leitura que, segundo Cervetti, Pardales e Damico (2001), deixa de ser entendida como um processo de extração de um sentido preconcebido para um processo de construção em que leitores são entendidos como construtores de significação.

Indo ao encontro do que discute Cervetti, Pardales e Damico (2001) sobre a ampliação do conceito de leitura, Menezes de Souza (2011a; 2011b), argumenta sobre a importância de entendermos a leitura como construída sócio-historicamente nas comunidades (heterogêneas) das quais pertencemos e somos por elas constituídos. Para isso, segundo o autor, é necessário percebermo-nos como complexos e heterogêneos, e que os significados por nós produzidos são sempre situados e, portanto, múltiplos, uma vez que refletem valores e fundamentos das comunidades das quais fazemos parte.

Em relação à prática docente, o professor precisa desenvolver autonomia, ou seja, valorizar seus próprios saberes, entendendo seu contexto local como espaço onde se pode construir conhecimentos válidos e pertinentes ao invés de apenas (tentar) pôr em prática o que pesquisadores ou especialistas, distantes do contexto de atuação docente, planejaram (KUMARAVADIVELU, 2001). Isto é, uma percepção crítica de que métodos ou planejamentos pré-estabelecidos por terceiros, e não sensíveis a especificidades contextuais, não condizem com as necessidades exigidas na sociedade contemporânea.

Além disso, com o desenvolvimento da percepção crítica nos alunos, esses podem vir a ser agentes críticos a partir de uma cidadania participativa (KALANTZIS; COPE, 2000; MATTOS, 2015; BRASIL, 2006), voltada para o engajamento na vida política de sua comunidade, para a busca dos direitos e do cumprimento dos deveres de 
todos, ao entrarem em contato e produzirem novos sentidos a partir de diferentes formas e usos da linguagem.

Devido à multiplicidade, à diversidade semiótica de constituição de textos por meio dos quais os indivíduos se comunicam e se expressam, que se constituem numa sociedade também plural e heterogênea, acreditamos que os princípios da pedagogia dos multiletramentos (KALANTZIS; COPE, 2005), termo que designa a multiplicidade de usos da linguagem em práticas de leitura e escrita presentes na sociedade contemporânea, possam nortear as práticas docentes para contemplar tal complexidade e diversidade.

Kalantzis e Cope (2005) entendem que a constituição do conhecimento de um indivíduo acontece por meio de quatro ações básicas, mas que ao pensarmos a aprendizagem como design, isto é, entender a aprendizagem como um processo de construção, de produção de conhecimento - meaning making - e não a mera reprodução, essas ações básicas se tornam 'movimentos'. Pois a noção de movimento indica certo dinamismo e, portanto, não implica uma sequência linear, em que as 4 'ações' (uma após a outra) deveriam ser mobilizadas nas atividades/aulas. Assim, os quatro movimentos pelos quais o conhecimento se constitui, segundo Kalantzis e Cope (2005) são: ‘experienciar', 'conceituar', 'analisar' e 'aplicar.

O primeiro movimento, 'experienciar', ocorre através da imersão ou exposição ao 'novo' que precisa ter alguns aspectos ou elementos familiares para que não seja contraprodutivo e seja percebido, pelo aluno, como aprendível. Logo, o movimento 'experienciar' consiste na relação entre o 'conhecido' e o 'novo'. Já o movimento 'conceituar' envolve um distanciamento da experienciação do cotidiano para que haja uma expansão do conhecimento através da análise de estruturas, causas e relações que, por vezes, podem desafiar o senso comum. É um processo que envolve, além de conceituar, as habilidades de generalizar e sintetizar.

O movimento 'analisar' envolve um engajamento para se interpretar uma lógica subjacente de certo conhecimento, ação, objeto ou representação: identificar propósitos, questionar intenções e interesses implícitos e explícitos, interpretar perspectivas e intenções daqueles que destas se beneficiam. E, por fim, o movimento 'aplicar', que requer um agir (produzir e não reproduzir) de forma ativa, aplicando um conhecimento construído em um contexto familiar, isto é, em uma situação já experienciada, ou em 
um contexto diferente, que não seja familiar ao aprendiz, mas que essa aplicação do conhecimento envolva a transformação do mesmo.

\section{IMPACTOS DOS NOVOS LETRAMENTOS EM PRÁTICAS DE PROFESSORES DE INGLÊS EM FORMAÇÃO INICIAL OU CONTINUADA}

Esta seção aborda alguns exemplos de práticas pedagógicas descritas no livro Novos Letramentos, Formação de Professores e Ensino de Língua Inglesa (ZACCHI; STELLA, 2014), que demonstram, de forma mais evidente, os impactos das teorias dos novos letramentos nas práticas de professores de língua inglesa em formação inicial ou continuada, após terem contato com tais teorias.

\section{Estabelecendo uma relação entre o global e o local}

No texto de Mattos (2014), são apresentados alguns dados da pesquisa de doutorado da autora. Esses dados são atividades realizadas por uma professora do ensino médio de uma escola pública de Belo Horizonte, Minas Gerais. Porém, devido aos objetivos do presente artigo, analisaremos apenas uma sequência de duas atividades (leitura e escrita). Na primeira atividade, foi trabalhado o gênero 'página de internet'. A ideia foi retirada das Orientações Pedagógicas do Estado de Minas Gerais (OPedMG), que sugeria o uso de um texto sobre carrinho de bebê no próprio site, ou seja, utilizando computadores com acesso à internet. Porém, a professora preferiu utilizar o texto da página da Nokia em forma impressa.

A respeito dessa atividade de leitura envolvendo o site da Nokia, a professora argumenta que "foi uma atividade prazerosa porque os alunos adoram telefones celulares e eles gostam de saber informação sobre isso [...]" (Portfólio ${ }^{5}$ de Dora, p. 1011 apud MATTOS, 2014. p. 119), e afirma que "os alunos ficam envolvidos porque eles se interessam por telefones celulares [...]” (ibid.). Assim, podemos inferir que a professora pensou na relação do global com o local (MATTOS, 2015), ao substituir o texto e imprimi-lo, considerando a realidade local possível, demonstrando, também, certa autonomia em sua prática docente, com tomada de decisões sensíveis a seu contexto local de atuação (KUMARAVADIVELU, 2001).

\footnotetext{
${ }^{5}$ Cada professor participante (3 no total) da pesquisa de doutorado de Mattos (2014), Dora, por exemplo, registrava as atividades desenvolvidas, assim como suas respectivas reflexões em um portfólio que fora utilizado pela autora como fonte de dados para análise.
} 
A professora alega ter gostado da atividade, pois seus "alunos puderam falar de sua experiência de comprar produtos pela internet e explicar o que eles fizeram ou fariam quando/se a empresa não entrega o produto comprado" (Portfólio de Dora, p. 1011 apud MATTOS, 2014. p. 119). Com esse fragmento, percebe-se que, embora tenha escolhido um texto de uma empresa internacional, e que estaria, portanto, valorizando práticas globais, a maneira como a professora trabalhou o texto privilegiou as práticas locais dos alunos.

Dando continuidade, a professora propôs que seus alunos escrevessem, na sala de aula, uma carta de reclamação, considerando a hipótese da compra de um celular defeituoso através da internet. Segundo Mattos (2014), a professora corrigiu a primeira versão da carta, que foi feita em sala e, após a reescrita dos alunos, as cartas ainda apresentavam alguns "erros" mas que não foram corrigidos, demonstrando que "ela valorizou a produção dos alunos considerando boas e adequadas" (ibid. p. 121). Isto é, a professora valorizou o uso local, a negociação que os alunos fizeram do conhecimento que tinham da língua para alcançar seus objetivos, para uma tomada de ação diante de um problema e não a reprodução exata de um modelo do gênero carta de reclamação ou uma escrita que reproduzisse uma suposta maneira que seria próxima a de um nativo, por estar gramaticalmente correta, pois esses não eram os objetivos da atividade naquele momento. (CANAGARAJAH, 2006; MATTOS, 2015).

Observando a atividade de leitura, com base em Kalantzis e Cope (2005), percebemos que ela possibilita a aprendizagem dos alunos por meio do movimento 'experienciar', ao serem expostos ao gênero página de internet - site da Nokia - e ao relacioná-la com as experiências prévias dos alunos que fazem uso de páginas de internet fora da sala de aula, além do uso e compra de celulares.

Com a atividade de produção escrita, a professora possibilita que os alunos também construam conhecimento com o movimento 'experienciar', através da exposição a exemplos e à estrutura e objetivos do gênero carta de reclamação. E, por fim, através do movimento 'aplicar', em que os alunos utilizam o conhecimento construído em relação à página de internet, venda de celulares e do gênero carta de reclamação, para aplicar em outro contexto (hipotético) de reclamação de uma compra de um celular defeituoso, possibilitando, assim, que os alunos ajam de forma ativa em uma situação de relação de poder entre empresa e cliente em que o cliente exige uma providência frente ao problema com o produto comprado. Em outras palavras, a partir 
do uso localizado que fizeram do inglês, a atividade problematizou o papel do cidadão em uma situação na qual ele precisa agir de forma mais ativa para que não tenha seus direitos negados (COPE; KALANTZIS, 2000; MATTOS, 2015; BRASIL, 2006).

\section{Provocando um novo ponto de vista}

Mudando o contexto educacional, trazemos outro exemplo de sequência de atividades apresentada no texto de Ifa (2014). Essas atividades foram elaboradas e ministradas em quatro aulas, por uma instrutora (licencianda) de um curso de extensão de língua inglesa (para iniciantes), no projeto de extensão "Casa de Cultura no Campus" da Universidade Federal de Alagoas.

Nas duas primeiras aulas, com intuito de trabalhar a questão da homofobia, a instrutora fez um levantamento do conhecimento de mundo dos alunos relativo a concurso de beleza para homens e para mulheres e suas respectivas diferenças. Em seguida, exibiu um vídeo que apresenta candidatos de 27 países ao concurso de beleza gay. Após a discussão, entregou o texto Mr Gay raises storm in Africa que foi retirado de um site da África do Sul sobre um concurso de beleza gay que seria realizado em $2012^{6}$. As questões elaboradas pela instrutora para trabalhar o texto foram: "Que tema é abordado no texto? Quais os aspectos positivos e negativos de $\mathrm{Mr}$ Gay na África do Sul? Por que o texto foi escrito? (ou Qual o objetivo do texto?)" (IFA, 2014, p. 231-232, tradução nossa) ${ }^{7} \mathrm{Na}$ etapa seguinte, os alunos leram e discutiram os comentários dos sul-africanos a esse site que promovia o evento.

Vemos que, até esse momento, as atividades promovem certo embate entre saberes globais e locais (MATTOS, 2015), uma vez que há uma relação entre o conhecimento prévio dos alunos, que fora levantado pela instrutora, e o texto abordado na aula. No entanto, as questões elaboradas para a abordagem do texto apontam para uma prática de leitura com foco na busca de sentidos no texto, valorizando apenas seu contexto de produção. Dessa forma, tais questões privilegiam um saber global ao incentivar que os alunos/leitores apenas identifiquem sentidos/respostas no texto, ao invés de incentivarem que esses alunos/leitores construam sentidos a partir do que leem,

\footnotetext{
${ }^{6}$ Conforme explica Ifa (2014), as atividades apresentadas em seu texto foram desenvolvidas por uma orientanda de Iniciação Científica entre 2011 e 2012.

7 "What is the text about? What are the positive and negative aspects of Mr Gay in South Africa? Why was it written? (ou What is the objective of the text?)" (IFA, 2014, p. 231-232).
} 
problematizando e relacionando tais sentidos/respostas com seus contextos locais (cf. CERVETTI; PARDALES; DAMICO, 2001).

Em seguida, a instrutora questiona como os alunos se posicionariam, caso esse evento acontecesse em Maceió e, assim, ela consegue estabelecer uma relação entre o local e o global, como defende Mattos (2015).

$\mathrm{Eu}$ [a instrutora] fiz com que os alunos refletissem sobre a seguinte situação: se o evento fosse em Maceió, você seria a favor ou contra? Então dividi os grupos de acordo com suas opiniões compartilhadas e deixei que eles preparassem seus argumentos. Em seguida, abri para uma discussão com a turma toda. Tentei fazer como um debate de eleições, fazendo com que cada grupo se posicionasse e depois abrindo espaço para perguntas. (IFA, 2014, p. 235-236).

Essa atividade em grupos possibilita o posicionamento de diferentes perspectivas (pró e contra), bem como a problematização de tais perspectivas ao promover a interação entre esses grupos ao abrir "espaço para perguntas" (ibid.). Isso pode possibilitar a ruptura de concepções cristalizadas e, portanto, a expansão de perspectivas tanto dos alunos, como da própria instrutora, uma vez que oportuniza o compartilhamento de visões ou interpretações de um mesmo evento de acordo com o(s) sentido(s) construído(s) pelos alunos (MONTE MÓR, 2013; MENEZES DE SOUZA, 2011b).

Após a discussão, a instrutora pediu que os alunos elaborassem um texto, em inglês, revelando suas respectivas opiniões acerca da realização do evento hipotético em Maceió. O aspecto avaliado no texto foi "a capacidade de comunicação dos alunos" (IFA, 2014, p. 237) o que demonstra que a instrutora valorizou o uso local que os alunos fizeram do inglês (CANAGARAJAH, 2006).

Até o momento, a aula da instrutora possibilitou que os alunos construíssem conhecimento pelo movimento 'experienciar' (KALANTZIS; COPE, 2005), pois foram expostos a uma situação que ocorre na África do Sul, semelhante ao que ocorre na cidade que eles residem, estabelecendo, assim, uma relação entre o global e o local (MATTOS, 2015). Com a discussão baseada nas perguntas propostas pela professora, e no momento dos debates entre os grupos, percebemos a mobilização do movimento 'analisar', já que se busca entender uma lógica subjacente do texto e, a partir de então, discutem os prós e contras da realização de algo semelhante do que fora debatido, no contexto local dos alunos. 
$\mathrm{Na}$ terceira aula, a instrutora utiliza uma reportagem sobre um assassinato brutal de um casal gay em Maceió, demonstrando uma valorização dos saberes locais, como advoga Mattos (2015). Após a leitura, a turma foi dividida em dois grupos que deveriam preparar um role-play ${ }^{8}$, em inglês, no qual representariam os amigos e os pais das vítimas. Essa atividade demonstra um trabalho de produção de sentido a partir da leitura e discussão de um texto, além de possibilitar uma desestabilização de discursos dominantes e homofóbicos (BRASIL, 2006; CERVETTI; PARDALES; DAMICO, 2001). Embora o texto de Ifa (2014) não apresente evidências de que o role-play tenha provocado alguma mudança ou expansão de perspectiva dos alunos, entendemos que esse tipo de atividade possibilita certa desestabilização de discursos dominantes ao permitir que os alunos interpretem a situação a partir de uma posição, de um ponto de vista diferente (dos amigos e dos pais das vítimas) do que comumente se é assumido nos discursos homofóbicos, contribuindo, assim, para o respeito e a "convivência pacífica com as diferenças" (MENEZES DE SOUZA, 2011b, p. 139).

Por fim, na última aula, ao concluírem que um concurso de beleza não seria um bom evento para combater a homofobia em Maceió, a instrutora dividiu a turma em grupos, responsáveis por pensar em eventos que melhor combatessem a homofobia na cidade e, então, cada grupo deveria elaborar um cartaz, em inglês, promovendo tais eventos. Como podemos perceber, a conclusão acerca do concurso beleza não ser um bom evento para o combate a homofobia na cidade aponta para construção de um consenso, indo de encontro a uma perspectiva crítica que valoriza o questionamento e a problematização a partir de diferentes pontos de vista (MENEZES DE SOUZA, 2011b; MONTE MÓR, 2013). Isso porque a instrutora, ao sugerir uma atividade a partir do consenso estabelecido, não problematiza o porquê que tal evento não contribuiria para o combate a homofobia ou quais seriam as implicações desse evento para o contexto em questão.

Contudo, a atividade sugerida, embora trate de uma situação hipotética e não promova a avaliação de diferentes pontos de vistas (inclusive a homofóbica), permite que o aluno possa agir, possa ter uma tomada de ação, por meio da produção do cartaz, com vistas a promover um evento que melhor combateria a homofobia em Maceió que, em 2011, "apresentou a terceira taxa mais alta de homicídio a gays (dados obtidos no

${ }^{8}$ Encenação. 
relatório nacional de crimes homofóbicos, disponível em: www.ggb.org.br)" (IFA, 2014, p. 235).

Nota-se que, tanto o role-play quanto a elaboração do cartaz se caracterizam como produção de conhecimento por meio do movimento 'aplicar' discutido por Kalantzis e Cope (2005), uma vez que os alunos utilizam seus conhecimentos prévios e o conhecimento construído nas aulas anteriores para aplicar em uma nova situação, diferente das que foram estudadas.

\section{Ampliando os objetivos das aulas de inglês}

Para finalizar a apresentação dos estudos que tratam dos impactos das teorias dos novos letramentos em práticas pedagógicas, incluímos um terceiro contexto educacional. Nesse estudo, Costa (2014) toma como base os relatos individuais de experiências didático-pedagógicas do estágio supervisionado (presentes nos relatórios finais de licenciandos concluintes), no primeiro semestre de 2011 do curso de Letras Língua Inglesa da Universidade Federal de Campina Grande, Paraíba.

Embora o autor não apresente, nesse texto, exemplos concretos de atividades, uma vez que é apresentado apenas um recorte de sua pesquisa de pós-doutoramento, ele discute a respeito da incorporação das teorias dos novos letramentos nas aulas ministradas pelos licenciandos em suas práticas de estágio supervisionado. Tal incorporação pode ser percebida pelo objetivo de um minicurso intitulado English in a Multicultural World (EMW), que fora planejado e ministrado pelos licenciandos: “discutir como diferentes formas de expressão cultural em Língua Inglesa interferem nas construção da cidadania na atualidade, atentando para os problemas emergentes como o bullying e a formação de ideias pré-concebidas" (COSTA, 2014, p. 187); bem como pelos relatos que o autor apresenta no texto, como por exemplo o de uma das licenciandas concluintes: "ademais, acredito ter cumprido meu papel de educadora, uma vez que atingi os objetivos do Curso EMW e do Módulo II, incitando a participação dos alunos e promovendo discussões que colocaram em xeque seus valores [...]" (COSTA, 2014, 187-188).

Ao analisarmos esse relato e o objetivo do minicurso, na perspectiva dos graduandos, à luz do que discute (KALANTZIS; COPE, 2005), percebemos que são exemplos do movimento 'aplicar' (ibid.), uma vez que representam a aplicação das teorias, vistas nas aulas teóricas da disciplina de estágio, no momento de suas práticas. 
Em relação ao objetivo do minicurso, percebemos que este propicia atividades que convergem com uma perspectiva crítica do ensino de língua inglesa, possibilitando uma ampliação dos objetivos do ensino dessa LE para além de questões meramente linguísticas e estruturais.

Podemos afirmar que, de forma geral, os exemplos abordados nas três subcategorias desse artigo, se analisados pela perspectiva dos professores participantes, representam o movimento 'aplicar' (KALANTZIS; COPE, 2005), pois os professores tiveram contato com as teorias dos novos letramentos em oficinas, projetos ou cursos de formação continuada ou inicial, e, posteriormente, aplicaram-nas em contextos reais de sala de aula.

\section{CONSIDERAÇÕES FINAIS}

As constantes transformações da sociedade contemporânea provocam mudanças nas formas de se relacionar, de se comunicar, de se expressar, de entender a cidadania e, também, de ensinar/educar. Na pesquisa realizada (PIBIC/CNPq 2015-2016), a análise das práticas orientadas pelos novos letramentos presentes no livro Novos letramentos, formação de professores e ensino de língua inglesa (ZACCHI; STELLA, 2014), cujos autores/colaboradores são pesquisadores brasileiros de diversas IES e integrantes do Projeto Nacional Novos Letramentos, evidenciou aspectos referentes à formação de professor e ao ensino de língua inglesa que apontam para uma maior interação ou a relação entre escola, sujeito e sociedade.

Com a análise das práticas pedagógicas apresentadas na obra investigada, percebemos que as práticas que demonstram, de forma mais evidente, os fundamentos dos novos letramentos são as que sugerem um deslocamento de práticas tradicionais de ensino para práticas que usam a disciplina de língua inglesa como um meio para se alcançar "a construção de personalidades morais, autônomas e críticas" (ARAÚJO, 2000, p. 98), aspectos mais educacionais e formativos do aluno/cidadão que fazem parte desse "mundo complexo, globalizado e múltiplo" (MENEZES DE SOUZA, 2011a, p. 279).

Percebemos que as práticas orientadas pelos novos letramentos da obra analisada provocaram, nos alunos, o desenvolvimento da cidadania participativa e da habilidade de negociação para que possam se engajar ativamente nas diferentes comunidades (heterogêneas) das quais fazem parte na sociedade atual. Com isso, eles (e os 
professores também) podem entender a linguagem como prática sociocultural e com natureza política, além de se perceberem como sujeitos situados sócio-historicamente. E, por consequência, entenderem as interpretações e as verdades consideradas únicas como contingentes e situadas, levando-os a serem mais abertos e tolerantes com a opinião e a diferença do outro. Para isso, os alunos e os professores precisaram se deslocar daqueles papeis posicionados em uma hierarquia vertical, na qual o professor detém o conhecimento que deveria ser 'transmitido' para o aluno, no sentido da educação bancária discutida por Paulo Freire (MENEZES DE SOUZA, 2011a). Logo, ambos passam a enxergar o conhecimento como sendo construído e não transmitido (e preconcebido).

Tais práticas delineiam o papel do professor de inglês na contemporaneidade. Além das questões discutidas anteriormente, o professor precisa assumir uma postura crítica e reflexiva em relação a sua prática, e, assim, desenvolver autonomia e autoria para tomar decisões sensíveis às necessidades de seu contexto de atuação e não mais seguir métodos ou princípios tidos como universais. É necessário, também, entender os sujeitos envolvidos (alunos e professores) como construtores, como produtores de conhecimento. E, portanto, desenvolver uma prática docente que propicie a construção desse conhecimento, como sugere a pedagogia dos multiletramentos (KALANTZIS; COPE, 2000; 2005), por exemplo. Os princípios dessa pedagogia podem ser uma alternativa norteadora das práticas docentes para que os professores possam contemplar tal complexidade e diversidade, uma vez que a aprendizagem é vista como construção, que se daria por meio dos movimentos 'experienciar', 'conceituar', 'analisar' e 'aplicar' (KALANTZIS; COPE, 2005). Movimentos esses que não se constituem como um método, ou princípios universais, apenas orientam e/ou tornam os professores conscientes de como suas escolhas e práticas provocarão no aluno a construção de conhecimento por meio de diferentes formas, ou movimentos (ibid.).

Como podemos perceber, para se alcançar tais objetivos, para que a educação, o ensino de inglês especificamente, seja mais condizente com as necessidades e as complexidades da sociedade contemporânea, os pressupostos das teorias aqui abordadas apontam para certa autonomia do professor para que o mesmo possa, como sugere Kumaravadivelu (2001), teorizar sobre sua prática e praticar o que teoriza. Com isso, evitar a simplificação ou a neutralização das diferenças e das complexidades entre os sujeitos e os contextos de ensino ao tentar seguir métodos, princípios ou modelos 
universais que não condizem com o mundo globalizado, tecnologizado e complexo no qual vivemos.

\section{REFERÊNCIAS BIBLIOGRÁFICAS}

ARAÚJO, U. F. Escola, democracia e a construção de personalidades morais. In: Educação e Pesquisa, São Paulo, v. 26, n. 2, p. 91-107, jul./dez. 2000.

BRASIL. Secretaria de Educação Básica. Orientações curriculares para o ensino médio: Linguagens, códigos e suas tecnologias. Brasília: MEC/SEB, v. 1, 2006, p. 85 124.

CANAGARAJAH, S. After disinvention: possibilities for communication, community and competence. In: MAKONI, S.; PENNYCOOK, A. (Ed.). Disinventing and reconstituting languages. Clevedon: Multilingual matters Ltd., 2006, p. 233-239.

CERVETTI, G.; PARDALES, M. J.; DAMICO, J. S. A tale of differences: comparing the traditions, perspectives and educational goals of critical reading and critical literacy. Reading Online, v. 4, n. 9, 2001.

COPE, B.; KALANTZIS, M. (Ed.). Multiliteracies: literary learning and the design of social futures. London: Routledge, 2000.

COSTA, M. A. M. Uma análise sobre a inserção das teorias dos novos letramentos e multiletramentos em um curso de formação docente. In: ZACCHI, V.; STELLA, P. R. (Orgs.). Novos letramentos, formação de professores e ensino de língua inglesa. Maceió: Edufal, 2014, p. 181-198.

IFA, S. Reflexões sobre formação de professores e novos letramentos no projeto de extensão casas de cultura no campus da Universidade Federal de Alagoas. In: ZACCHI, V.; STELlA, P. R. (Orgs.). Novos letramentos, formação de professores e ensino de língua inglesa. Maceió: Edufal, 2014, p. 225-246.

KALANTZIS, M.; COPE, B. Learning by design. Melbourne, VSIC, 2005.

KNOBEL, M; LANKSHEAR, C. (eds.) A new literacies sampler. New York: Peter Lang, 2007.

KRESS, G. Multimodality. In: COPE, B.; KALANTZIS, M. (Ed.). Multiliteracies: literacy learning and the design of social futures. London: Routledge, 2000, p. 182-202.

KUMARAVADIVELU, B. Toward a Postmethod Pedagogy. TESOL Quartely, vol. 35, no. 4, 2001.

MATTOS, A. M. A. Novos Letramentos, Globalização e Ensino de Inglês como Língua Estrangeira. In: ZACCHI, V.; STELLA, P. R. (Orgs.). Novos letramentos, formação de professores e ensino de língua inglesa. Maceió: Edufal, 2014, p. 101-136. 
MATTOS, A. M. A. Ensino de Inglês como Língua Estrangeira na Escola Pública: Letramentos, Globalização e Cidadania. Jundiaí: Paco Editorial, 2015.

MONTE MÓR, W. Crítica e letramentos críticos: reflexões preliminares. In: ROCHA, C.H.; MACIEL, R. F. Língua estrangeira e formação cidadã: por entre discursos e práticas. Campinas: Pontes, 2013, p. 31-50.

MENEZES DE SOUZA, L. M. T. O professor de inglês e os letramentos no século XXI: Métodos ou ética? In: JORDÂO, C. M.; MARTINEZ, J.Z.; HALU, R. C. (Orgs.). Formação "desformatada": Práticas com professores de língua inglesa. Campinas: Pontes, 2011a, p. 279-303.

MENEZES DE SOUZA, L. M. T. Para uma redefinição de letramento crítico: conflito e produção de significação. In: MACIEL, R. F.; ARAUJO, V. A. (Orgs.) Formação de professores de línguas: ampliando perspectivas. Jundiaí: Paco Editorial, 2011b, p. 128140.

ZACCHI, V.; STELLA, P. R. (Orgs.). Novos letramentos, formação de professores e ensino de língua inglesa. Maceió: Edufal, 2014. 